\title{
Pengaruh Berat Katalis Zeolit Alam terhadap Pencairan Limbah Ban dalam Bekas Kendaraan Bermotor Roda Dua Menjadi Bahan Bakar Cair
}

\author{
Lince Muis $^{1}$, Ira Galih Prabasari ${ }^{1 *}$, Nana Suyana ${ }^{1}$ \\ ${ }^{1}$ Program Studi Teknik Kimia Universitas Jambi \\ Jln. Tribrata Km. 11 Pondok Meja, Kec. Mestong, Kabupaten Muaro Jambi 36364 \\ *e-mail: iragalih@gmail.com
}

\begin{abstract}
The productivity of Indonesia's tire industry is expected to be higher following the growth of domestic and global motor vehicle production. Along with that, waste used tires that are not used in the environment are increasing. Rubber-based tires, is one type of synthetic polymer (Polystyrene). Polystyrene cannot be easily recycled so that the processing of polystyrene waste must be done properly so as not to harm the environment. Polystyrene pyrolysis process is one way to minimize the polystyrene waste. The pirlolysis process is carried out with temperature operating conditions of $400 \mathrm{oC}$, weight of tire rubber 3000 grams with variations of catalyst $2 \%$, $4 \%$ and $6 \%$ for 3 hours. The results showed that the more catalysts used the\% CHP Conversion produced would be greater, the best results on the $6 \%$ catalyst were as much as $41.073 \%$. Based on the results of the analysis using GC-MS, Used inner tire pyrolysis oil has the following hydrocarbon chains: $\left(C_{1}-C_{5}\right)$ as much as $0.33 \%,\left(C_{5}-C_{12}\right)$ as much as $88.96 \%$ and $\left(C_{10}-C_{28}\right) 10.71 \%$. Hydrocarbon compounds contained in the oil from used tire pyrolysis contain many aromatic compounds
\end{abstract}

Keywords: Tire Waste, Pyrolysis, Polystyrene

\section{Pendahuluan}

Kebutuhan energi masih didominasi oleh bahan bakar fosil tidak terbarukan yang cepat atau lambat pasti akan habis ketersediaannya seperti minyak bumi, gas alam, dan batubara (Arita dkk, 2015). Dari tahun 2010 hingga tahun 2015 produksi minyak mentah dan gas alam di Indonesia mengalami penurunan. Produksi minyak mentah pada tahun 2010 sebesar 344.888,00 barrel dan pada tahun 2015 sebesar $286.814,20$ barrel. Sedangkan produksi gas alam pada tahun 2010 sebesar 3.407.592,30 MMscf dan pada tahun 2015 sebesar 2.948.365,80 MMscf (BPS, 2017). Jumlah produksi yang terus menurun tersebut menyebabkan adanya kelangkaan bahan bakar, sehingga dibutuhkan adanya bahan bakar alternatif untuk mengatasi kebutuhan energi.

Produktivitas pertumbuhan industri ban Indonesia diperkirakan akan semakin tinggi mengikuti pertumbuhan produksi kendaraan bermotor domestik dan global. Hal ini bisa dilihat dengan jumlah kendaraan bermotor dan mobil di jalan raya yang semakin padat. Berdasarkan data yang diperoleh dari Mabes Polri, jumlah kendaraan yang terdaftar di Indonesia per tanggal 1 Januari 2018 mencapai 111 Juta, atau tepatnya 111.571.239 unit kendaraan. Angka tersebut termasuk jumlah sepeda motor yang memberikan kontribusi terbesar sebanyak 82\% atau 91.085.532 unit sepeda motor. Mobil pribadi memberikan kontribusi $12 \%$ atau sebanyak 13.253.143 unit mobil. Kontribusi lainnya berasal dari mobil bus, mobil barang, dan kendaraan khusus. Jika produksi motor atau mobil semakin bertambah, tentunya produksi ban itu sendiri akan semakin meningkat. Data Kementerian Perindustrian (Kemenperin) saat ini terdapat 13 produsen ban yang siap untuk produksi berbagai ban untuk pasar domestik maupun international dan telah mampu berproduksi berbagai tipe dan ukuran ban. Baik untuk mobil penumpang, truk, bus dan kendaraan berat. Kemampuan produksi untuk tipe-tipe ban itu mencapai lebih dari 75 juta ban per tahun, sedangkan untuk ban sepeda motor kapasitasnya mencapai 55 juta ban per tahun.

Seiring dengan itu, limbah ban-ban bekas yang tidak terpakai di lingkungan pun semakin meningkat. Hal ini dapat mencemari lingkungan karena material ban tidak mudah terurai secara biologis (Arita dkk, 2015). Ban berbahan dasar karet, merupakan salah satu jenis polimer sintetis (Polistirena). Polistirena tidak dapat dengan mudah didaur ulang sehingga pengolahan limbah polistirena harus dilakukan secara benar agar tidak merugikan lingkungan. Proses pirolisis polistirena merupakan salah satu cara untuk meminimalisir limbah polistirena tersebut (Damayanthi dan Retno, 2009).

Proses produksi hidrokarbon cair dari Polistirena dapat dikerjakan dengan proses pirolisis. Pirolisis atau devolatilisasi adalah proses fraksinasi material oleh suhu. Proses pirolisis dimulai pada temperatur sekitar $230{ }^{\circ} \mathrm{C}$, ketika komponen yang tidak stabil secara termal, dan volatile matters pada sampah akan pecah dan menguap bersamaan dengan komponen lainnya. Produk cair yang menguap mengandung tar dan polyaromatic hydrocarbon. Produk pirolisis selain dipengaruhi oleh suhu dan waktu, juga oleh laju pemanasan (Rodiansono, 2007).

Berdasarkan penelitian terdahulu Arita dkk (2015), melakukan pirolisis karet ban dengan variabel tetap, yaitu 500 gram karet ban bekas, dengan suhu uap (permukaan) pirolisis sekitar $200 \mathrm{oC}$ dan tekanan $1 \mathrm{~atm}$, serta ukuran karet ban bekas yaitu $0,5 \times 0,5 \mathrm{~cm}$. Sedangkan variabel bebas yaitu waktu operasi (2 jam, 3 jam) dan berat katalis (100 gram, 200 gram, 300 gram, 400 gram, serta tanpa katalis). Hasil penelitian diperoleh hasil volum bahan bakar dengan waktu pirolisis 2 jam didapat hasil volume terbanyak pada berat katalis 400 gram didapat $54,5 \mathrm{ml}$ bahan bakar, sedangkan pada waktu pirolisis 3 jam di dapat hasil volume terbanyak pada berat katalis 400 gram sebanyak 73,5. Dari hasil analisis GC (Gas Chromatography) disimpulkan bahwa sampel yang diperoleh dari penelitian merupakan hidrokarbon cair jenis premium.

Tujuan dari penelitian ini yaitu untuk mengetahui pengaruh penambahan berat katalis yang digunakan dalam proses pencairan limbah ban dalam bekas kendaraan bermotor roda dua terhadap konversi yang dihasilkan. Dan untuk mengetahui karakteristik bahan bakar cair yang 
dihasilkan dari proses pencairan limbah ban dalam bekas kendaraan bermotor roda dua.

\section{Metode Penelitian}

Penelitian ini menggunakan imbah ban dalam bekas kendaraan bermotor roda dua jenis polistirena dan katalis zeolit alam Dalam penelitian ini menggunakan 3 macam variabel, yaitu: Variabel Terkontrol adalah \% Konversi, Variabel Bebas yang digunakan berat katalis yaitu (2\%, 4\% dan $6 \%$ ) berat ban bekas, dan Variabel tetap yang digunakan dalam penelitian ini adalah berat karet ban 3000 gram, tekanan $1 \mathrm{~atm}$, dan suhu $400{ }^{\circ} \mathrm{C}$.

\subsection{Perancangan Alat Rcceaktor}

Reaktor pirolisis jenis batch yang dibuat dari bahan besi yang berukuran diameter $30 \mathrm{~cm}$ dan tinggi $50 \mathrm{~cm}$. Rancangan reaktor dapat dillihat pada Gambar 1.

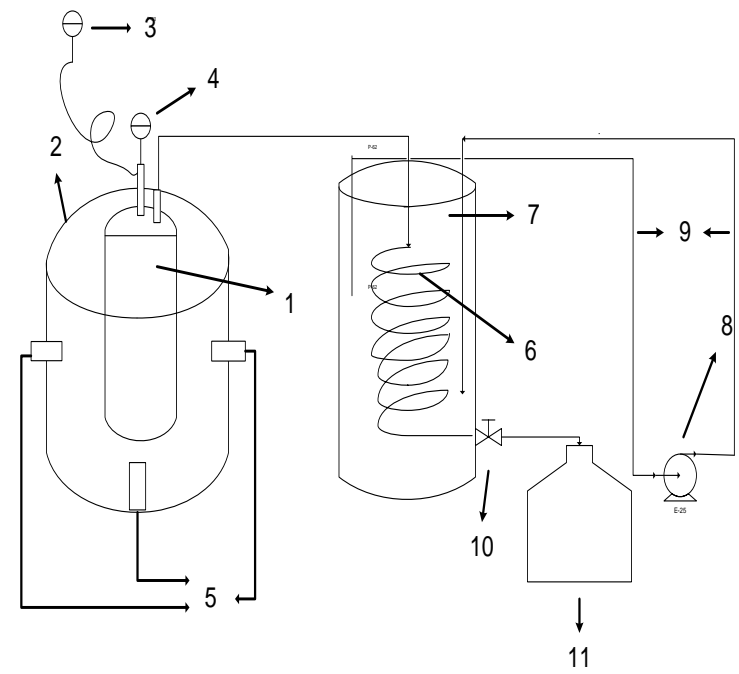

Gambar 1. Rangkaian alat pencairan limbah ban bekas

Keterangan :

1.Reactor, 2. Plate ( Rockwool ), 3. Pressure Gauge, 4. Termocouple, 5. Kompor ( 3 buah kompor ), 6. Coil 7. Drum, 8. Pump, 9. Selang, 10. Valve, 11. Wadah minyak.

\subsection{Persiapan Bahan}

Limbah ban bekas (polistirena) berupa ban dalam kendaraan motor yang diambil dari usaha bengkel motor kemudian dicuci untuk menghilangkan kotoran yang menempel pada ban bekas kemudian dikeringkan, dan Karet ban bekas dipotong kecil-kecil dengan ukuran $2 \mathrm{~cm} \times 2 \mathrm{~cm}$.
Katalis zeolit alam sebanyak 100 gram di stirer dengan larutan $\mathrm{NaOH}$ 1,5 M sebanyak $300 \mathrm{ml}$ selama 3 jam kemudian dicuci menggunakan aquades hingga $\mathrm{pH}$ netral dan dikeringkan didalam oven dengan suhu $105{ }^{\circ} \mathrm{C}$ selama 2 jam, lalu katalis zeolit alam dikalsinasi didalam furnace dengan suhu $500{ }^{\circ} \mathrm{C}$ selama 5 jam.

\subsection{Proses Pencairan Limbah ban bekas}

Ban yang telah dipotong-potong dengan ukuran $2 \mathrm{~cm}$ x 2 $\mathrm{cm}$ ditimbang sebanayak 3000 gram, kemudian dicampurkan dengan katalis sebanyak (60 gram, 120 gram dan 180 gram) dimasukkan kedalam reaktor dan diatur pada kondisi operasi suhu $400{ }^{\circ} \mathrm{C}$ dan tekanan 1 atm selama 3 jam. Hasil produk gas dikondensasikan dan ditampung ke dalam wadah minyak.

\subsection{Analisis Data}

1. Analisis GC-MS

Analisis kandungan minyak hasil pencairan karet ban bekas menggunakan GC-MS (Gas Cromatografy Mass Spektroscopy). Kromatografi gas (KG) merupakan metode pemisahan suatu campuran menjadi komponen-komponen berdasarkan interaksi fasa gerak dan fasa diam. Fase gerak berupa gas yang stabil sedangkan fase diam bisa zat padat atau zat cair. Cuplikan yang dapat dipisahkan dengan metode ini harus mudah menguap. Cuplikan dalam bentuk uap dibawa oleh aliran gas ke dalam kolom pemisah, hasil pemisahan dapat dianalisis dari kromatogram. (Sholihah, 2018).

\section{Analisis Persen Konversi}

$$
\begin{aligned}
& \% \text { konversi }= \\
& 100 \%
\end{aligned}
$$

\section{Hasil dan pembahasan}

\subsection{Pengaruh Penambahan Katalis Terhadap Konversi Bahan Bakar yang dihasilkan}

Pada penelitian ini menggunakan ban dalam bekas kendaraan bermotor roda dua jenis polistirena (PS) sebagai bahan baku dan zeolit alam sebagai katalis. Proses pirolisis karet ban dalam bekas menjadi bahan bakar cair dilakukan dengan temperatur $400{ }^{\circ} \mathrm{C}$, berat karet ban 3000 gram dengan variasi berat katalis 2\%, 4\% dan 6\% (60 gram, 120 gram dan 180 gram) dari bahan baku. Hasil dari pirolisis ban dalam bekas disajikan pada Tabel 1 .

\subsection{Persiapan Katalis}

\begin{tabular}{|c|c|c|c|c|c|}
\hline No & Temperatur & Berat Ban & Berat Katalis & Berat Minyak Pirolisis & \% Konversi \\
\hline 1 & & & 60 gram & 604,85 gram & $20,162 \%$ \\
\hline 2 & $400{ }^{\circ} \mathrm{C}$ & 3000 gram & 120 gram & 1080,85 gram & $36,028 \%$ \\
\hline 3 & & & 180 gram & 1232,19 gram & $41,073 \%$ \\
\hline
\end{tabular}

Tabel 1. Huasil pirolisis limbah ban dalam bekas

Penggunaan katalis diharapkan dapat meningkatkan produk cairan hasil pirolisis melalui proses pemutusan ikatan rangkap pada senyawa polistirena yang merupakan komponen karet ban. Dari hasil yang diperoleh pada Tabel 1 dan Gambar 1 konversi minyak yang didapat meningkat seiring bertambahnya jumlah katalis yang digunakan, hasil konversi tertinggi pada berat katalis 180 gram yaitu 41,073\%. Menurut Sa'diyah (2015), Fungsi utama katalis 
pada proses ini adalah memecah hidrokarbon rantai panjang. Jumlah katalis yang banyak akan mendegradasi hidrokarbon rantai panjang menjadi senyawa yang lebih sederhana melalui pembentukan radikal bebas. Tiap radikal bebas yang dihasilkan akan menginduksi senyawa lain hingga terbentuk radikal baru dengan jumlah atom yang lebih kecil.

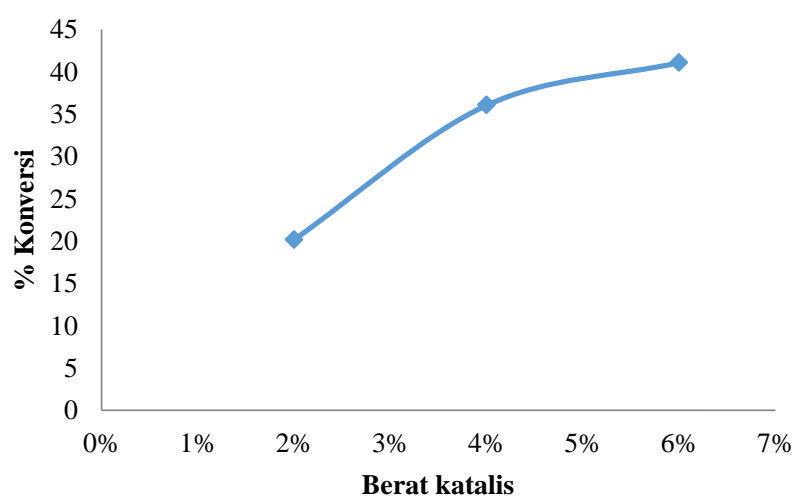

Gambar 1. Grafik hubungan barat katalis terhadap \% konversi

\subsection{Karakaristik Bahan Bakar Cair yang dihasilkan Cair yang dihasilkan}

Bahan bakar cair yang dihasilkan dari proses pirolisis ban dalam bekas kendaraan bermotor roda dua kemudian dianalisis untuk mengetahui karakteristiknya.

\section{Analisis GC-MS}

Hasil pirolisis karet ban dalam bekas yang memiliki konversi tertinggi yaitu 41,073\% dengan berat katalis 180 gram dianalisis menggunakan GC-MS (Gas Cromatografy Mass Spektroscopy). Analisis menggunakan GC-MS (Gas
Chromatography Mass Spectroscopy) dapat mengukur jenis dan kandungan senyawa dalam suatu sampel baik secara kualitatif dan kuantitatif. Instrumen ini merupakan perpaduan dari dua buah instrumen, yaitu Kromatografi Gas yang berfungsi untuk memisahkan senyawa menjadi senyawa tunggal dan Spektroskopi Massa yang berfungsi mendeteksi jenis senyawa berdasarkan pola fragmentasinya. Berikut spektra GC dapat dilihat pada Gambar 2.

Berdasarkan spektra GC pada Gambar 2, minyak hasil pirolisis ban dalam bekas memiliki 5 puncak tertinggi, puncak tertinggi berada pada waktu retensi 5,82 menit. Berikut tabel senyawa yang teridentifikasi didalam minyak hasil pirolisis ban dalam bekas.

Berdasarkan pada Tabel 3.2. diatas senyawa-senyawa yang terdapat pada minyak hasil pirolisis ban dalam bekas memiliki rantai hidrokarbon sebagai berikut: $\left(\mathrm{C}_{1}-\mathrm{C}_{5}\right)$ sebanyak $0,33 \%,\left(\mathrm{C}_{5}-\mathrm{C}_{12}\right)$ sebanyak $88,96 \%$ dan $\left(\mathrm{C}_{10}-\mathrm{C}_{28}\right)$ $10,71 \%$. Senyawa hidrokarbon yang terdapat pada minyak hasil pirolisis ban dalam bekas banyak mengandung senyawa aromatis, dimana senyawa aromatis merupakan turunan dari senyawa hidrokarbon minyak bumi dimana difungsikan sebagai komponen bahan bakar.

Gugus aromatik mempengaruhi pembakaran pada bahan bakar (fuel) karena tidak mudah terbakar. Pembakaran fuel yang diinginkan adalah yang menghasilkan tekanan maksimum terhadap penurunan piston. Hal ini bergantung tergantung dari ketepatan waktu pembakaran agar jumlah energi yang ditransfer ke piston maksimum.

Ketepatan waktu pembakaran tergantung dari jenis rantai hidrokarbon yang selanjutnya menentukan kualitas fuel. Karena gugus aromatis sulit terbakar maka energi yang ditransfer ke piston lebih besar sehingga meningkatkan performa mesin. Presentase aromatis yang terlalu tinggi dalam fuel juga tidak diperbolehkan karena mencemari lingkungan dan berbahaya bagi kesehatan (Sa'diyah, 2015).

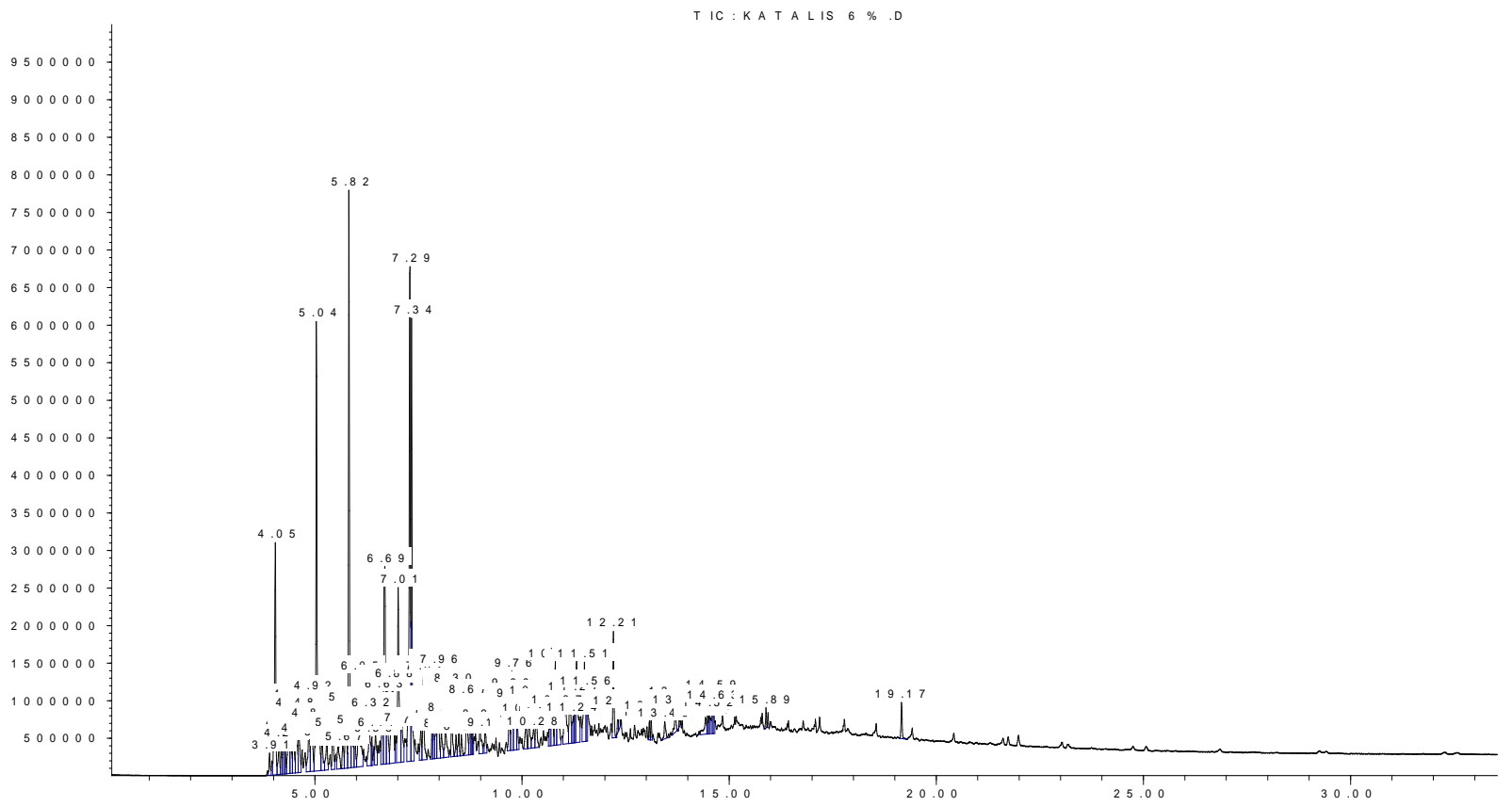

Gambar 3.2. Spektra GC Minyak Pirolisis Ban Bekas 
Tabel 3.2. Senyawa-senyawa pada minyak hasil pirolisis ban

\begin{tabular}{|c|c|c|c|}
\hline No & $\%$ Area & Rumus Molekul & Senyawa \\
\hline 1 & 0,33 & $\mathrm{C}_{1}-\mathrm{C}_{5}$ & Isobutene \\
\hline & & & $\begin{array}{l}\text { Xylene, p-xylol, methylbenzol, cyclohepta-1,3,5-triene, o-cymol, p-cymol, d- } \\
\text { limonene, cyclohexane, 1,2-dimethylcyclopropane, trimethylethylene, 1-methyl-2- } \\
\text { ethylbenzene, cumene, 2,6-dimethylnaphthalane, p-cymene, o-allyltoluene, } \\
\text { propenylbenzene, p-toluquinaldine, naphthalene, 1,2,3-trimethylbenzene, sorbic } \\
\text { aldehyde, 2-methyl-2,4-hexadiene, 1,2,3-trimethylindene, 2,3-dimethyl-1H-indene, }\end{array}$ \\
\hline & & & \\
\hline 2 & 88,96 & $\mathrm{C}_{5}-\mathrm{C}_{12}$ & 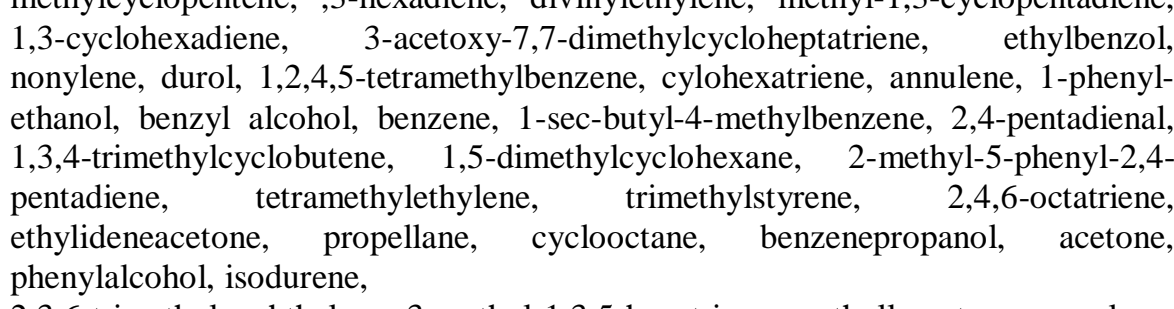 \\
\hline & & & $\begin{array}{l}\text { 2,3,6-trimethylnaphthalene, 3-methyl-1,3,5-hexatriene, methyllaurate, camazulene, } \\
\text { 1,4,5,8-tetramethylnaphthalene, 1-Propylnaphthalene, valencene, } 10,11- \\
\text { dihydrophenanthrene, }\end{array}$ \\
\hline 3 & 10,71 & $\mathrm{C}_{10}-\mathrm{C}_{28}$ & $\begin{array}{l}\text { dihydrophenanthrene,phthalate, } 1,2 \text { benzenedicarboxylic acid, isooctyl phthalate, } \\
\text { tricyclodecaene, 5,5-dimethyl-3-oxo, tetradecane, heptadecanonitrile, 4,6,8- } \\
\text { trimethylazulene, 2,3,6-trimethylnaphthalene, n-icosane, n-tetradecane, 1-methyl- } \\
9,10 \text {-dihidrophenanthrene, hexadecane, 1-cetene, 2-nonadecanone, } \\
\text { heptadecanone, 1-pentadecene,3,4-dimethyl-1,1-biphenyl, pentadecane. }\end{array}$ \\
\hline
\end{tabular}

\section{Kesimpulan}

Pengaruh berat katalis terhadap konversi bahan bakar yang dihasilkan menunjukkan bahwa semakin banyak berat katalis yang digunakan maka \% konversi bahan bakar akan semakin banyak, berdasarkan data \% konversi terbanyak pada berat katalis 180 gram yaitu 41,073\%.

Karakteristik bahan bakar cair yang diperoleh dari hasil analisis GC-MS minyak hasil pirolisis ban dalam bekas memiliki rantai hidrokarbon sebagai berikut: $\left(\mathrm{C}_{1}-\mathrm{C}_{5}\right)$ sebanyak $0,33 \%,\left(\mathrm{C}_{5}-\mathrm{C}_{12}\right)$ sebanyak $88,96 \%$ dan $\left(\mathrm{C}_{10}-\mathrm{C}_{28}\right)$ $10,71 \%$. Senyawa hidrokarbon yang terdapat pada minyak hasil pirolisis ban dalam bekas banyak mengandung senyawa aromatis.

\section{Daftar Pustaka}

Arita. S., Assalami. A., Naibaho. D. I. 2015. Proses Pembuatan Bahan Bakar Cair dengan Memanfaatkan Limbah Ban Bekas Menggunakan Katalis Zeolit. Jurnal Teknik Kimia, 02(21) : 8-14.

Asron F., Falaah., Adi Cifriadi. 2012. Pemanfaatan Limbah Ban Bekas Dengan Menggunakan Teknologi Pirolisis. Jurnal Warta Perkaretan : 103- 107.

BPS. 2017. Produksi Minyak Bumi dan gas Alam 19962015.

Buekens, A.G., Huang, H. 1998. Catalytic plastics cracking for recovery of gasolinerange hydrocarbons from municipal plastic wastes. Resources, Conservation and Recycling, 23 : 163-181.

Damayanthi. R dan Martini. R. 2009. Proses Pembuatan Bahan Bakar Cair dengan Memanfaatkan Limbah Ban Bekas Menggunakan Katalis Zeolit Y dan ZSM-5. Jurnal Teknik Kimia. Semarang : Universitas Diponegoro
Handono Roy. 2017. Pembuatan Bahan Bakar Cair dengan Memanfaatkan Limbah Ban Bekas Menggunakan Katalis dari Limbah Bekas Perengkahan Minyak Bumi PT. Pertamina Ru III Dengan Metode Pirolisis. Palembang : Universitas Muhammadiyah Palembang.

Hutomo. S. G., Winarno. J. 2015. Studi Karakteristik Dekomposisi Termal. Temperatur Tinggi Ban Bekas Untuk Mendapatkan Bahan Bakar Gas Alternatif. Jurnal Teknik, 1(5) : 40-46.

Kementrian perindustrian. 2018. Industri Ban Kian Prospektif.

Merve Sogancioglu., Esra Yel., Gulnare Ahmetli. 2017. Investigation of the Effect of Polystyrene (PS) Waste Washing Process and Pyrolysis Temperature on (PS) Pyrolysis Product Quality. Energy Procedia, 118 : 189194.

Rodiansono., Trisunaryati. W., Triyono. 2007. Pembuatan, Karakterisasi dan Uji Aktifitas Katalis NiMo/Z pada Reaksi Hidrorengkah Fraksi Sampah Plastik Menjadi Fraksi Bensin. Jurnal Berkala MIPA : 2-17.

Sa'diyah. Khalimatus., Juliastuti., S.R. 2015. Pengaruh Jumlah Katalis Zeolit Alam Pada Produk Proses Pirolisis Limbah Plastik Polipropilen (PP). JBAT, 4(2): 40-45.

Saputra. A. E., Rahman. M. Aminy. Y.A. 2006. Produksi Bahan Bakar Ramah Lingkungan Melalui Proses Pirolisis Limbah Ban. Jurnal JPE, 20(2): 26-31.

Setiadi, dan Pertiwi, A., 2007. Preparasi dan Karakteristik Zeolite Alam untuk Konversi Senyawa Abe menjadi Hidrokarbon. Jurnal Teknik Kimia.

Sholihah Atti. 2018. Analisis Kramatografi Gas. BPPT

Syamsiro. M. 2015. Kajian Pengaruh Penggunaan Katalis Terhadap Kualitas Produk Minyak Hasil Pirolisis Sampah Plastik. Jurnal Teknik, 5(1): 47-56. 
Syamsiro. M., Sulistiawati. Y., Ridwan. M., Dwicahyo. M.

2016. Studi Pirolisis Sampah Ban untuk Produksi

Bahan Bakar Minyak Alternatif bagi Industri Kecil dan

Menengah. Jurnal Riset Daerah, 15(3): 2511-2521. 